\title{
Analisis Nilai Tambah Proses Pengolahan Kopi Arabika Gayo pada Kabupaten Centra Produksi di Aceh
}

\author{
Emmia Tambarta Kembaren, S.P., M.Si·a, Taufiqurrahman, S.P. b \\ aFakultas Pertanian Universitas Malikussaleh - Lhokseumawe, Email: emmia.tambarta@unimal.ac.id \\ bAktivis Peneliti Kopi Arabika Gayo - Aceh Timur
}

\section{Article Info}

Article history:

Received 18 February 2021

Received in revised from 23 February 2021 Accepted 26 April 2021

\section{DOI:}

https://doi.org/10.32938/ag.v6i2.1316

Keywords:

Added Value

Agro-industry

Arabica gayo coffee

\begin{abstract}
Abstrak
Indonesia known as one of the biggest coffee exporter in the world after Brazil, Vietnam, dan Colombia. Aceh is one of the central production areas of Arabica Coffee Comodity in Indonesia. This study aims to determine the difference of Gayo Arabica coffee beans added value based on the processing in Aceh Tengah and Bener Meriah Regency. This research located in two central production of coffee in Aceh. Both Regency ware the main location for coffee production in Aceh. This research used in-depth interviews with decision makers in green been coffee agro-industry which has largest export quantity in Aceh Tengah and Bener Meriah which are Baitul Qiradh (KBQ) Baburrayyan Cooperative and Permata Gayo Cooperative as data collection method. The Respondents were the Manager of KBQ Baburrayan; Mr. Moch. Charis, S.T. and the Manager of Permata Gayo Cooperative; Mr. Jumhur, S.P. his Research used descriptive quantitative method with Hayami analysis. The result showed that the added value of labui coffee beans to green coffee beans in Aceh Tengah Regency was higher which is Rp. 28,337/kg by $38.40 \%$ ratio when compared to green bean coffee in Bener Meriah Regency which is $R p$. 26,738 / $\mathrm{kg}$ by $37.14 \%$ ratio. This result wes caused by: (1) the price of green beans in Aceh Tengah Regency is higher than in Bener Meriah Regency, (2) the green bean production process in Aceh Tengah Regency tends to use more modern technology so that it can reduce labor costs and produce added value which higher than Bener Meriah Regency.
\end{abstract}

\section{Pendahuluan}

Indonesia adalah negara produsen kopi terbesar ketiga di dunia setelah Brazil dan Vietnam. Nilai ekspor kopi Indonesia pada tahun 2017, menempati urutan ke empat di Indonesia setelah kelapa sawit, karet, dan kelapa. Nilai ekspor kopi mencapai 1,19 Milyard USD (Susanti, 2018). Hal ini membuktikan bahwa kopi merupakan salah satu komoditi ekspor yang memiliki potensi untuk dikembangkan.

Kontribusi komoditi kopi terhadap perekonomian Indonesia adalah sebagai sumber devisa negara, sumber pendapatan petani, penciptaan lapangan pekerjaan, pembangunan wilayah, pendorong agribisnis dan agroindustri, serta pendukung konservasi lingkungan. International Coffee Organization [ICO] (2018) dalam Sudjarmoko (2013) menyebutkan bahwa saat ini Indonesia merupakan penghasil kopi terbesar ketiga di dunia setelah Brazil dan Vietnam. (Sudjarmoko, 2013)

Aceh adalah salah satu daerah penghasil kopi terbesar di Indonesia. Data BPS Aceh tahun 2019 menunjukkan bahwa terdapat Tiga Kabupaten yang menjadi sentra produksi kopi Arabika di Provinsi Aceh seperti yang terlampir pada diagram sebagai berikut:

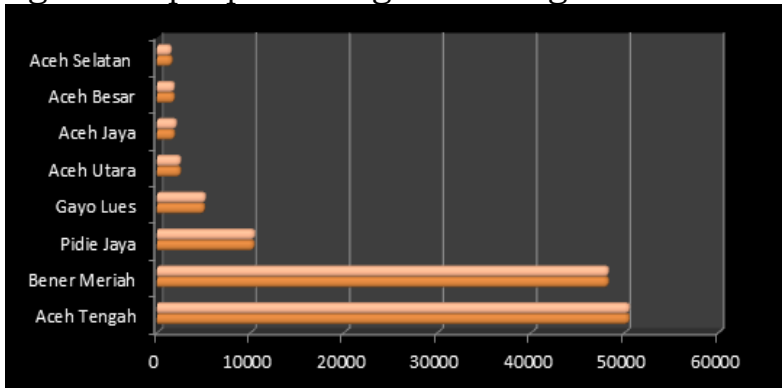

(Sumber : BPS tahun 2019)

Aroma, rasa dan body dari Kopi Gayo cukup dikenal oleh dunia perdagangan internasional. Cita rasa kopi arabika gayo ini bisa dibuktikan dengan cupping test/ tes cita rasa. Meski terjadi krisis di Eropa, tak mengurangi permintaan kopi asal dataran tinggi Tanah Gayo di pasar dunia. Peluang yang ada untuk menumbuh kembangkan wawasan agroindustri kopi ini antara lain mencakup berbagai aspek seperti: lingkungan strategis, permintaan, sumber daya dan teknologi.

Pembangunan agroindustri yang diterapkan adalah pembangunan agroindustri yang berkelanjutan. Agroindustri yang dibangun dan dikembangkan harus memperhatikan aspek- 
aspek manajemen dan konservasi Sumber Daya Alam sebagai wujud dari keunggulan komperatif Indonesia (Tambarta et al., 2016).

Jenis produk olahan kopi yang diperdagangkan bisa berupa cherry, labui, gabah dan green bean. Kabupaten Bener Meriah secara umum mengeluarkan kopi dalam bentuk biji kopi arabika (green bean). Perdagangan gabah kopi dan bubuk hanya dalam jumlah kecil. Perdagangan biji kopi arabika dari daerah ini hampir 90 persen dari total volume perdagangan kopi keluar Kabupaten Aceh Tengah dan Kabupaten Bener Meriah (Tambarta et al., 2016).

Pengembangan nilai tambah pada komoditas kopi Arabika Gayo diharapkan dapat menghasilkan produk diversifikasi kopi olahan yang mempunyai arti penting, karena dapat menjadi komoditas unggulan yang mempunyai daya saing tinggi di pasar internasional. Kopi Gayo sebagai perwakilan kopi dari Indonesia yang beriklim tropis, disamping berpeluang untuk pengembangan produk diversifikasi kopi olahan tersebut diatas. Peningkatan nilai tambah ini diharapkan dapat menjadi dasar dalam peningkatan daya saing perdagangan kopi Indonesia.

Proses pengolahan akan meningkatkan nilai tambah produk kopi. Perhitungan nilai tambah dihitung berdasarkan proses pengolahan di dua lokasi centra produksi yang berbeda. Perbedaan proses pengolahan di dua lokasi centra produksi tentu akan menghasilkan nilai tambah yang berbeda. Berdasarkan rumusan masalah di atas maka permasalahan utama penelitian ini adalah Proses pengolahan pada lokasi centra kopi manakah yang memiliki nilai tambah terbesar di Aceh.

Berdasarkan rumusan masalah di atas maka permasalahan utama penelitian ini adalah Proses pengolahan pada lokasi centra kopi manakah yang memiliki nilai tambah terbesar di Aceh.Tujuan dari penelitian ini adalah untuk melihat nilai tambah produk kopi di Kabupaten Aceh Tengah dan Bener Meriah.

\section{Metode Penelitian}

Penelitian ini dilakukan pada dua daerah sentra produksi kopi di Aceh yaitu Kabupaten Bener Meriah dan Aceh Tengah. Metode pengumpulan data yang digunakan adalah wawancara mendalam dengan Pengambil keputusan pada agroindustri green been coffee yang memiliki kuota ekspor terbesar di Kabupaten Aceh Tengah yaitu Koperasi Baitul Qiradh (KBQ) Baburrayyan dan Kabupaten Bener Meriah yaitu Koperasi Permata Gayo. Data yang digunakan dalam penelitian ini adalah data sekunder dan data primer. Data sekunder dikumpulkan dari laporan instansi terkait yakni Badan Pusat Statistik Bener Meriah dan Aceh Tengah. Data skunder yang digunakan adalah data luas lahan dan produksi biji kopi arabika. Data Primer didapat dengan wawancara mendalam dengan pihak pengambil keputusan pada agroindustri yang terkait yakni Koperasi KBQ Baburrayan dan Koperasi Permata Gayo.

Responden dari penelitian ini adalah Manajer KBQ Baburrayan yakni Bpk. Moch. Charis, S.T. dan Manajer Koperasi ayo Permata yakni Bpk. Jumhur, S.P.

Metode penelitian yang digunakan adalah Deskriptif Kuantitatif dengan alat analisis Hayami. Hayami (1987) menyebutkan bahwa perhitungan nilai tambah didasarkan pada satu satuan bahan baku utama. Adapun perhitungan nilai tambah menggunakan metode hayami dapat dilihat pada tabel berikut:

Tabel 1. Perhitungan nilai tambah

\begin{tabular}{lll}
\hline Variabel & Satuan & Notasi \\
\hline Output,input dan harga & \multicolumn{3}{l}{} \\
Output/produk total & $\mathrm{kg} /$ proses produksi & $\mathrm{A}$ \\
Input bahan baku & $\mathrm{kg} / \mathrm{proses}$ produksi & $\mathrm{B}$ \\
Input tenaga kerja & $\mathrm{HOK} /$ proses produksi & $\mathrm{C}$ \\
& $\mathrm{Kg} \mathrm{output/Kg} \mathrm{bahan}$ \\
Faktor konversi & $\mathrm{baku}$ & $\mathrm{D}=\mathrm{a} / \mathrm{b}$ \\
Koefisien tenaga kerja & $\mathrm{HOK} / \mathrm{Kg}$ bahan baku & $\mathrm{E}=\mathrm{c} / \mathrm{b}$ \\
Harga Output & $\mathrm{Rp} / \mathrm{Kg}$ & $\mathrm{F}$ \\
Upah rata-rata tenaga kerja & $\mathrm{Rp} / \mathrm{proses}$ produksi & $\mathrm{G}$ \\
Pendapatan dan Keuntungan & & \\
Harga input bahan baku & $\mathrm{Rp} / \mathrm{Kg}$ & $\mathrm{H}$ \\
Sumbangan input lain & $\mathrm{Rp} / \mathrm{Kg}$ & $\mathrm{I}$ \\
Nilai Output & $\mathrm{Rp} / \mathrm{Kg}$ & $\mathrm{J}=\mathrm{d} \times \mathrm{f}$ \\
Nilai tambah & $\mathrm{Rp} / \mathrm{Kg}$ & $\mathrm{K}=\mathrm{j}-\mathrm{h}-\mathrm{i}$ \\
Rasio nilai tambah & $\%$ & $\mathrm{~L}=\mathrm{k} / \mathrm{j}$ x $100 \%$ \\
Pendapatan tenaga kerja & $\mathrm{Rp} / \mathrm{Kg}$ & $\mathrm{M}=\mathrm{e}$ x g \\
Bagian tenaga kerja & $\% \mathrm{~N}=\mathrm{m} / \mathrm{kx} 100 \%$ \\
\hline
\end{tabular}




\begin{tabular}{lll}
\hline Keuntungan & $\mathrm{Rp} / \mathrm{Kg}$ & $\mathrm{O}=\mathrm{k}-\mathrm{m}$ \\
$\begin{array}{l}\text { Bagian Keuntungan } \\
\text { Balas jasa untuk faktor produksi }\end{array}$ & $\%$ & $\mathrm{P}=\mathrm{o} / \mathrm{j} \times 100 \%$ \\
Marjin & $\mathrm{Rp} / \mathrm{Kg}$ & $\mathrm{Q}=\mathrm{j}-\mathrm{h}$ \\
a. Pendapatan tenaga kerja & $\%$ & $\mathrm{R}=\mathrm{m} / \mathrm{q} \times 100 \%$ \\
b. Sumbangan input lain & $\%$ & $\mathrm{~S}=\mathrm{i} / \mathrm{q} \times 100 \%$ \\
$\quad$ a. Keuntungan & $\%$ & $\mathrm{~T}=\mathrm{o} / \mathrm{q} \times 100 \%$ \\
\hline
\end{tabular}

Sumber: Hayami et al., (1987)

Ada beberapa variabel yang terkait dalam analisis nilai tambah ini. Faktor konversi, menunjukan banyaknya produk olahan yang dihasilkan dari satu kilogram bahan baku. Koefisien tenaga kerja, menunjukan banyaknya tenaga kerja langsung yang diperlukan untuk mengolah satu satuan input. Sedangkan nilai produk menunjukan nilai output yang dihasilkan dari satu satuan input. Nilai input lain mencangkup nilai dari semua korbanan selain bahan baku dan tenaga kerja langsung yang digunakan selama produksi berlangsung (Hayami et al., 1987).

\section{Hasil dan Pembahasan}

Pengolahan hasil merupakan subsektor agribisnis yang sangat besar peranannya dalam meningkatkan nilai tambah dari hasil pertanian yang telah diperoleh. Dalam kondisi perekonomian dimana sektor industri harus dikembangkan secara berimbang dengan pengembangan sektor lain seperti sektor pertanian yang mendukung sektor industri. Hal ini sejalan dengan penelitian Tambarta (2016) yang menyebutkan bahwa sektor pertanian harus dikembangkan secara sinergis dari hulu (budi daya) sampai ke hilir (pemasaran). Tujuannya adalah untuk meningkatkan dan memperbaiki taraf hidup masyarakat menjadi lebih terjamin dan layak (Soekartawi, 2016).

Salah satu komoditas yang potensial untuk diolah ialah kopi. Pengolahan biji kopi menjadi kopi beras dan kopi bubuk dapat dilakukan oleh petani dan pihak industri. Adapun pihak ndustri yang menjadi responden dalam penelitian ini adalah Koperasi KBQ Baburrayan dan koperasi Permata Gayo. Pemilihan kedua koperasi ini dilakukan dengan alasan bahwa koperasi KBQ Baburrayan merupakan koperasi terbesar di daerah Kabupaten Aceh Tengah dan koperasi Permata Gayo merupakan koperasi terbesar di Bener Meriah. Kedua koperasi ini menghasilkan produk olahan biji kopi yang terintegrasi mulai dari petani binaan hingga eksportir.

Petani di luar koperasi mengolah kopinya dengan cara tradisional, menggunakan alat sederhana, sedangkan petani yang merupakan anggota koperasi sudah melakukan pengolahan menggunakan mesin (modernisasi). Konsep nilai tambah adalah suatu pengembangan nilai yang terjadi karena adanya input yang diperlakukan pada suatu komoditas. Input yang menyebabkan terjadinya nilai tambah dari suatu komoditas dapat dilihat dari adanya perubahan-perubahan pada komoditas tersebut, yaitu perubahan bentuk, tempat, dan waktu.

Pada awal perkembangan kopi di Dataran Tinggi Gayo di tahun 1950an, sebagian besar petani menggunakan proses pengolahan kering, karena bagi mereka lebih memudahkan. Namun pada tahun 1980an, dengan terus berkembangnya pasar dan bertambahnya pelaku ekonomi dari luar Aceh, pengolahan basah semakin populer.

Pada awal perkembangan kopi di Dataran Tinggi Gayo di tahun 1950an, sebagian besar petani menggunakan proses pengolahan kering, karena bagi mereka lebih memudahkan. Namun pada tahun 1980an, dengan terus berkembangnya pasar dan bertambahnya pelaku ekonomi dari luar Aceh, pengolahan basah semakin populer.

Proses pengolahan green kopi dimulai dari pengelolaan pasca panen yang terdiri dari petik buah merah dan sortasi awal (memisahkan biji busuk dengan biji merah). Proses selanjutnya adalah fermentasi dan pencucian. Proses Fermentasi dan pencucian di kedua Kabupaten ini menggunakan metode semi washed (semi-basah) dan washed (basah). Hanya sedikit daerah yang menggunakan system pengolahan dry (kering). Sistem washed membutuhkan air yang lebih banyak karena proses pencuciannya berulang-ulang. Biji kopi yang telah difermentasi akan dimasukkan ke dalam mesin pulper untuk mengupas kulit pertama (kulit merah) Hasil produk biji kopi yang dikupas ini disebut gahab kopi. Abah kopi kemudian dijemur hingga mencapai kadar air 18-17\%. Gabah yang telah dikeringkan akan dimasukkan ke dalam mesin huller untuk pengelupasan kulit ari. Hasil produk yang telah dikupas disebut labui kopi. Labui kopi akan dikeringkan kembali hingga mencapai kadar air $12 \%$.

Proses selanjutnya adalah grading dan sortasi. Biji green bean kopi harus disortasi secara fisik atas dasar ukuran dan cacat bijinya. Kotoran-kotoran non kopi seperti serpihan daun, kayu atau kulit kopi, harus juga dipisahkan. Namun ada sedikit perbedaan pada proses sortasi di kedua Kabupaten centra produksi ini. Kabupaten Aceh Tengah melakukan kegiatan sortasi 
dengan menggunakan teknologi industri 4.0 sedangkan Kabupaten Bener Meriah melakukan sortasi dengan teknologi semi modern. Kegiatan sortasi di Kabupaten Aceh tengah dilakukan dengan mesin yang dapat memisahkan kualitas produk green bean dengan sistem komputasi sensor warna. Secara umum olahan biji kopi Arabika Gayo di Kabupaten Aceh Tengah dan Bener Meriah dibagi menjadi empat yaitu : (1) Biji Cherry (Biji Kopi Merah, (2) Biji Gabah Kopi, (3) Biji Labui Kopi, (4) Green bean Kopi. Namun produk olahan kopi yang menjadi objek penelitian ini hanya terbatas pada proses pengolahan labui ke green bean. Hal ini karena produk green bean merupakan produk akhir yang dihasilkan oleh kedua Kabupaten centra produksi ini.

Nilai tambah pada sistem produksi biji green bean kopi ditentukan oleh kualitas biji labui kopi, proses penjemuran sampai mencapai kadar air 12-13\%, proses grading dan sortasi baik manual ataupun mekanis serta keterampilan tenaga kerja yang melakukan setiap fase kegiatan. Perhitungan nilai tambah biji labui kopi menjadi biji green bean kopi dapat dilihat pada Tabel berikut:

Tabel 2. Perbandingan Nilai Tambah Pada Sistem Pengolahan Biji Labui Kopi menjadi Green bean Kopi di Kabepaten Aceh Tengah dan Kabupaten Bener Meriah pada Tahun 2019.

\begin{tabular}{lrr}
\hline Output,input dan harga & & \\
Output (Biji Green Bean) & 87.871 & 48.336 \\
Input bahan baku (Biji Labui) & 107.160 & 60.420 \\
Input tenaga kerja & 7.230 & 10.160 \\
Faktor konversi & 0,82 & 0,80 \\
Koefisien tenaga kerja & 0,067 & 0,168 \\
Harga Output & 90.000 & 90.000 \\
Upah rata-rata tenaga kerja & 7.000 & 6.250 \\
Pendapatan dan Keuntungan & & \\
Harga input bahan baku & 45.000 & 45.000 \\
Sumbangan input lain & 460 & 268 \\
Nilai Output & 73.800 & 72.000 \\
Nilai tambah & 28.340 & 26.732 \\
Rasio nilai tambah & 38.40 & 37.13 \\
Pendapatan tenaga kerja & 472 & 1,051 \\
Bagian tenaga kerja & 1,67 & 3,93 \\
Keuntungan & 28,337 & 26,738 \\
Bagian Keuntungan & 38.40 & 37.14 \\
Balas jasa untuk faktor produksi & & \\
Marjin & 28.800 & 27.000 \\
a. Pendapatan tenaga kerja & 1,64 & 3,89 \\
b. Sumbangan input lain & 1,60 & 1,00 \\
$\quad$ a. Keuntungan & 96,76 & 95,11 \\
\hline Sumber Data Primer (2019) diola
\end{tabular}

Sumber : Data Primer (2019) di olah.

Tabel di atas menjelaskan bahwa pengolahan biji kopi labui Arabika Gayo menjad biji green bean kopi yang dilakukan oleh Kabupaten Bener Meriah cenderung labih kecil yakni sebesar $60.420 \mathrm{Kg} /$ Bulan dibandingkan biji Pembelian biji kopi Arabika Gayo di Kabupaten Aceh Tengah yakni sebesar $107.160 \mathrm{Kg} /$ Bulan. Hal ini disebabkan oleh volume pasar di Kabupaten Aceh Tengah lebih besar sehingga volume produksi Kabupaten Aceh Tengah cenderung lebih besar.

Hasil penelitian menunjukkan bahwa Berdasarkan hasil penelitian yang dilakukan di Kabupaten Aceh Tengah dan Bener Meriah maka didapatkan kesimpulan bahwa nilai tambah pada proses biji labui kopi ke biji green bean kopi di Kabupaten Aceh Tengah lebih tinggi yakni sebesar Rp. 28,.337/ kg dengan rasio sebesar 38.40\% biji green bean kopi di Kabupaten Bener Meriah adalah sebesar Rp. 26,.738/ kg dengan rasio sebesar 37.14\%.

Hal ini disebabkan oleh (1) Harga green bean di Kabupaten Aceh Tengah lebih besar dari pada di Kabupaten Bener Meriah, (2) proses produksi green bean di Kabupaten Aceh Tengah cenderung menggunakan teknologi yang lebih moderen sehingga dapat mengurangi biaya tenaga kerja dan menghasilkan nilai tambah yang lebih tinggi dibandingkan dengan Kabupaten Bener Meriah.

Hasil pembahasan ini sejalan dengan penelitian Tambarta (2016) yang menyatakan bahwa KBQ Baburrayan di Aceh Tengah memiliki nilai tambah yang lebih baik dari koperasi lainnya di Kabupaten Bener Meriah dari segi nilai tambahnya. Hal ini karena KBQ Baburrayan menggunkan teknologi terbaik, tenaga kerja yang terampil, dan bahan baku yang terintegrasi. 


\section{Simpulan}

Nilai tambah pada proses biji labui kopi ke biji green bean kopi di Kabupaten Aceh Tengah lebih tinggi yakni sebesar Rp. 28,.337/ kg dengan rasio sebesar 38.40\% biji green bean kopi di Kabupaten Bener Meriah adalah sebesar Rp. 26-.738// kg dengan rasio sebesar 37.14\%. Hal ini disebabkan oleh (1) Harga green bean di Kabupaten Aceh Tengah lebih besar dari pada di Kabupaten Bener Meriah, (2) proses produksi green bean di Kabupaten Aceh Tengah cenderung menggunakan teknologi yang lebih modern sehingga dapat mengurangi biaya tenaga kerja dan menghasilkan nilai tambah yang lebih tinggi dibandingkan dengan Kabupaten Bener Meriah

\section{Referensi}

[BPS] Badan Pusat Statistik Aceh Tengah. 2019. Aceh Dalam Angka. Provinsi Aceh: BPS.

Hayami, Y., Kawagoe, T., \& Morooka, Y. (1987). Agricultural Marketing and Processing in Upland Java A Perspective From A Sunda Village (Masdjidin Siregar (ed.); 8th ed.). CGPRT Center

Susanti A.A, Akbar, 2018. Outlook Kopi. Jakarta: Kementrian Pertanian.

Soekartawi. 2016. Analisis Usahatani. Jakarta: UI-Press.

Sudjarmoko, B. 2013. Prospek Pengembangan Industrialisasi Kopi Indonesia. Sirinov, 1(3), 99110.

Tambarta, E., Tinaprilla, N., \& Adhi, A. K. (2016). Analysis Added-ValueAnd Development Strategic of Gayo Coffe Products in Bener Meriah Aceh. 5(11), 515-519. 